\title{
Prevalência de klebsiella pneumoniae em cães e seus tutores
}

\author{
Prevalence of Klebsiella pneumoniae in dogs and their tutors \\ Prevalencia de Klebsiella pneumoniae en perros y sus tutores
}

Recebido: 17/05/2021 | Revisado: 22/05/2021 | Aceito: 01/06/2021 | Publicado: 14/06/2021

Juliana Marques Mencarelli

ORCID: https://orcid.org/0000-0002-0836-8075

Universidade José do Rosário Vellano, Brasil

E-mail: julianamarquesmencarelli@yahoo.com.br

Bethânia Elias Costa

ORCID: https://orcid.org/0000-0002-8514-9028

Universidade José do Rosário Vellano, Brasil

E-mail: bethaniaelias@hotmail.com

Géssica Corrêa Gonçalves

ORCID: https://orcid.org/0000-0002-0886-9347

Universidade José do Rosário Vellano, Brasil

E-mail: gessica.goncalves@unifenas.br

André Gomes Faria

ORCID: https://orcid.org/0000-0003-3364-1288

Universidade José do Rosário Vellano, Brasil

E-mail: andrefaria15.232@gmail.com

Angélica Cristina de Souza

ORCID: https://orcid.org/0000-0002-4013-6354

Universidade Federal de Lavras, Brasil

E-mail: angelicacsouza.acs@gmail.com

Clara de Mello Silva Oliveira

ORCID: https://orcid.org/0000-0001-7850-6579

Universidade José do Rosário Vellano, Brasil

E-mail: mellodeca@gmail.com

Marcelo Fabiano Gomes Boriollo

ORCID: https://orcid.org/0000-0002-9917-6203

Universidade Estadual de Campinas, Brasil

E-mail: marcelofgb@yahoo.com.br

Philipi Coutinho de Souza

ORCID: https://orcid.org/0000-0003-4497-7211

Universidade José do Rosário Vellano, Brasil

E-mail: philipi.souza@unifenas.br

José Antônio Dias Garcia

ORCID: https://orcid.org/0000-0002-4024-3045

Universidade José do Rosário Vellano, Brasil

E-mail: jadiasgarcia@gmail.com

Wilson Roberto Mesquia Oliveira

ORCID: https://orcid.org/0000-0002-5564-4757

Universidade José do Rosário Vellano, Brasil

E-mail: wilson.oliveira@unifenas.br

Pedro Ivo Sodré Amaral

ORCID: https://orcid.org/0000-0002-2366-2088

Universidade José do Rosário Vellano, Brasil

E-mail: Pedro.amaral@unifenas.br

Nelma de mello Silva Oliveira

ORCID: https://orcid.org/0000-0002-1114-2018

Universidade José do Rosário Vellano, Brasil

E-mail: nelma.oliveira@unifenas.br

\section{Resumo}

A Klebsiella pneumoniae (bactéria gram negativa e imóvel) é encontrada no trato intestinal de mamíferos. Quando ocorre um desequilíbrio as bactérias multiplicam-se intensamente, ocasionando doenças infecciosas. Portanto o objetivo deste artigo é correlacionar à prevalência dos isolados de animais, com a microbiota existente nas mãos dos proprietários, alertando sobre o risco da transmissão cruzada. Foram utilizados 114 cães para coleta de amostras, realizadas em diferentes sítios anatômicos e das mãos do proprietário, utilizando swabs estéreis umedecidos em $2 \mathrm{~mL}$ solução de salina tamponada (PBS) colocados em um tubo de ensaio. Posteriormente, $0,1 \mathrm{~mL}$ de cada diluição foram cultivadas nas placas de ágar MacConkey incubadas em condições de aerobiose à temperatura de $37^{\circ} \mathrm{C}$ por 24 horas. Em seguida foram realizadas provas bioquímicas e utilização de ágar cromogênico para triagem das amostras 
suspeitas de Klebisiella spp. Depois, foi realizada identificação por meio de espectrofotometria de massa. Foram coletadas, de 114 cães, 456 amostras de diversos sítios anatômicos entre animais e tutores. Das 456 amostras, 70 $(15,35 \%)$ apresentaram características semelhantes às de Klebsiella spp após triagem em provas bioquímicas e no Chromagar. Em relação ao número de amostras, das 70 sugestivas de Klebsiella, 9 amostras (12,85 \%) foram confirmadas. Com o presente estudo, foi confirmada a presença de Klebsiella pneumoniae em oito cães e em um tutor. $\mathrm{E}$, ainda, constatou-se que mais estudos são necessários para desvendar a possibilidade de transmissão, assim como o mecanismo para que isso ocorra.

Palavras-chave: Klebsiella pneumoniae; Transmissão cruzada; Bactéria; Microbiota.

\begin{abstract}
Klebsiella pneumoniae (gram negative and immobile bacteria) is found in the intestinal tract of mammals. When an imbalance occurs, the bacteria multiply intensely, causing infectious diseases. Therefore, the objective of the article is to correlate the prevalence of animal isolates, with the existing microbiota in the hands of the owners, warning about the risk of cross-transmission. $114 \mathrm{dogs}$ were used to collect samples, performed at different anatomical sites and on the owner's hands, using sterile swabs moistened in $2 \mathrm{~mL}$ phosphate buffered saline solution (PBS) placed in a test tube. Subsequently, $0.1 \mathrm{~mL}$ of each dilution was cultured on the MacConkey agar plates incubated under aerobic conditions at $37^{\circ} \mathrm{C}$ for 24 hours. Then, biochemical tests and chromogenic agar were used to screen suspected samples of Klebisiella spp. and the definitive identification was performed using mass spectrophotometry. 456 samples were collected from $114 \mathrm{dogs}$ from various anatomical sites between animals and guardians. Of the 456 samples, $70(15.35 \%)$ showed characteristics similar to Klebsiella spp after screening in biochemical tests and in Chromagar. Regarding the number of samples, of the 70 suggestive of Klebsiella, 9 samples (12.85\%) were confirmed. with the present study, the presence of Klebsiella pneumoniae was confirmed in eight dogs and one guardian. And it was found that more studies are needed to unveil the possibility of transmission, as well as the mechanism for it to occur.
\end{abstract}

Keywords: Klebsiella pneumoniae; Cross-transmission; Bacteria; Microbiota.

\title{
Resumen
}

Klebsiella pneumoniae es una (bacteria gram negativa inmóvil) que se encuentra en el tracto intestinal de animales y humanos. Cuando ocurre un desequilibrio, las bacterias comienzan a multiplicarse intensamente, provocando enfermedades infecciosas. Por tanto, el objetivo del artículo es correlacionar la prevalencia de aislados animales, con la microbiota existente en manos de los propietarios, advirtiendo sobre el riesgo de transmisión cruzada. Se utilizaron 114 perros para recolectar muestras, realizadas en diferentes sitios anatómicos y en las manos del propietario, utilizando hisopos estériles humedecidos en $2 \mathrm{~mL}$ de solución salina tamponada (PBS) colocados en un tubo de ensayo. Posteriormente, se cultivaron $0,1 \mathrm{~mL}$ de cada dilución en las placas de agar MacConkey incubadas en condiciones aeróbicas a $37^{\circ} \mathrm{C}$ durante 24 horas. El crecimiento de colonias rosadas, mucoides en agar MacConkey, las cuales se consideraron sospechosas de Klebsiella spp. Después de 24 horas, las colonias con tinción azul metálico indicaron la presencia de Klebsiella pneumoniae. Una colonia aislada se replicó en el medio de Infusión CerebroCorazón y se incubó durante 24 horas, enviada al Laboratorio Bruker en Brasil para realizar la técnica de Desreplicación, donde se identificarán moléculas con características de Klebsiella pneumoniae. Los datos se expresaron mediante análisis estadístico descriptivo. Se dispone de poca información sobre Klebsiella pneumoniae en perros y se necesitan más estudios para correlacionar la prevalencia de estas bacterias en animales y en el hombre.

Palabras clave: Klebsiella pneumoniae; Transmisión cruzada; Bacterias; Microbiota.

\section{Introdução}

Klebsiella pneumoniae é uma bactéria gram negativa imóvel que faz parte da família Enterobacteriaceae. É um patógeno oportunista que pode ser encontrado participando da microbiota natural do intestino, faringe, boca e pele dos mamíferos (Mungloo-rujubali et al., 2013; Koneman, 2008; Zhao et al., 2010). Porém, no trato intestinal, é considerada menos comum (Brooks et al., 2014).

Enterobacteriaceae, como as do gênero Klebsiella, podem ser isoladas em várias espécies animais e em humanos (Silva et al., 2005; Umeh, 2019). Elas são relatadas como causa de infecções primárias da corrente sanguínea, pneumonias, infecções do trato urinário e, até mesmo, cutâneas além de otites em animais. Já foram encontradas em superfícies de mucosas de mamíferos, em fezes de aves e no meio ambiente (Zetun, 2009; Aquino e Herzig, 2018). Em seres humanos, várias espécies dessa família podem acarretar numerosos processos patogênicos que incluem abscessos, meningites, sepses, pneumonias, infecções do trato urinário, infecções gastrointestinais, colonização de cateteres e infecções em feridas operatórias. Esses 
patógenos podem infectar pessoas e animais imunocomprometidos, sendo considerados organismos oportunistas (Koneman et al., 2008).

Dentre o gênero Klebsiella, a espécie mais descrita na medicina veterinária é Klebsiella pneumoniae. Esta é a principal causa de infecções do trato urinário (ITU) superior e inferior em cães e gatos (Aquino e Herzig, 2018), mas também já foi descrita como causa de endocardites, infecções pós-operatórias de pele e tecidos moles e em abscessos hepáticos (Hirsh et al., 2004).

Cepas de Klebsiella pneumoniae são agentes com grande capacidade de adquirir resistência a antimicrobianos, assim se tornando uma preocupação de saúde pública (Santiniello et al 2020), principalmente por estarem presentes na microbiota natural ou causando infecções em animais que são utilizados em terapias assistidas ou simplesmente em animais de estimação (Effah,2020).

Foram relatadas, por Marques et al., 2020, linhagens clonais de Klebsiella pneumoniae entre humanos saudáveis e cães que vivem em contato próximo, sugerindo que os cães apresentem papel de reservatórios dessas bactérias.

Assim, o objetivo do presente trabalho é correlacionar à prevalência dos isolados de Klebsiella pneumoniae dos sítios anatômicos dos animais (mucosa oral, retal, vaginal ou prepucial) com a microbiota existente nas mãos de seus tutores, gerando reflexões sobre o risco de transmissão cruzada, principalmente pelo contato direto entre as espécies.

\section{Metodologia}

O presente estudo foi realizado no Hospital Veterinário e no Laboratório de Biologia e Fisiologia de Microrganismos da Universidade José do Rosário Vellano mediante a aprovação do Comitê de Ética no uso de Animais (CEUA) - Protocolo 26A/2016 e Humano (Plataforma Brasil - Sistema CEP, Comitê de Ética em Pesquisa) - 18.77.208 da Universidade José do Rosário Vellano. As análises confirmatórias foram realizadas no Laboratório de Microbiologia de Alimentos da Universidade Federal de Lavras (UFLA) MG, Brasil.

Quanto metodologia de espectrometria de massa, é gerado um espectro de massa de acordo com o perfil proteico da bactéria e este pode ser utilizado na identificação em nível de gênero, espécie e, em alguns casos, subespécies, comparando-o com perfis depositados em bancos de dados (Assis, 2011; Carolina Axelsson, Ann-Sofi Rehnstam-Holm \& Bo Nilson, 2020).

\subsection{Animais e coleta das amostras}

As coletas foram realizadas em um período de nove meses em cães que compareceram para atendimento no Hospital Veterinário da Universidade José do Rosário Vellano. Foram utilizados 114 cães, tendo como critério de exclusão os cães com menos de 1 ano (filhotes) e aqueles que não receberam a autorização para coleta de amostras pelo tutor mediante Termo de Consentimento Livre e Esclarecido.

Para a realização do trabalho foram coletadas amostras clínicas de diferentes sítios anatômicos dos cães (cavidade oral, retal, vaginal ou prepucial) e das mãos do tutor, totalizando 456 amostras.

As coletas das amostras foram realizadas por meio de swabs estéreis umedecidos em Salina Tamponada de Fosfato (PBS) que foram friccionados em cada sítio anatômico do animal e na mão de seu tutor, a partir de movimentos circulares suaves. Os swabs utilizados na coleta foram colocados em um tubo de ensaio contendo 2 mL de solução de PBS e encaminhados para o Laboratório de Biologia e Fisiologia de Microrganismos da Universidade José do Rosário Vellano para a identificação prévia do microrganismo. Desta forma, foi feita uma triagem por métodos tintoriais, morfológicos e fisiológicos, a fim de sugerir a presença de Klebsiella pneumoniae. Posteriormente essas amostras sugestivas foram analisadas pela técnica de desreplicação (identificação de moléculas) por meio do equipamento MALDI-TOF para confirmação da presença da bactéria. 


\subsection{Processo de triagem para identificação de Klebsiella pneumoniae}

As amostras coletadas foram mantidas em PBS e, posteriormente, foram realizadas diluições seriadas de 10-1, 10-2 e 10-3. A seguir, foram cultivados $0,1 \mathrm{~mL}$ de cada diluição nas placas de ágar MacConkey para isolamento primário de todas as espécies de bacilos gram-negativos entéricos (Rios et al., 2020). As alíquotas de $0,1 \mathrm{~mL}$ foram distribuídas sobre o ágar com o auxílio de uma alça de platina descartável. As placas foram incubadas em condições de aerobiose à temperatura de $37^{\circ} \mathrm{C}$ por 24 horas, após esse período foi avaliado o crescimento de colônias róseo-amareladas de 1 a $7 \mathrm{~mm}$ de diâmetro, mucoides, lactoses positivas no ágar MacConkey, sendo consideradas suspeitas de Klebsiella spp (Munoz et al., 2007)

Após o crescimento de bactérias específicas (colônias róseo-amareladas, mucoides, lactoses positivas) para o tipo de ágar utilizado (MacConkey), foram realizadas provas bioquímicas para uma análise de diferenciação das bactérias da família Enterobacteriaceae por meio dos testes: Indol, Citrato, Vermelho de Metila, Voges- Proskauer (Rios et al., 2020),

Urease, Malonato, Lisina e ágar EMB (Eosin Methylene Blue Agar). Posteriormente, foram inoculadas de 3 a 5 colônias das amostras, que apresentaram características de Klebsiella spp nas provas bioquímicas, no ágar EMB e no ágar específico para o crescimento de Klebsiella spp (Chromagar Orientation) ( Mohammed et al., 2020).

Após 24 horas dessa inoculação, foi confirmada a presença de Klebsiella spp, por meio da análise da coloração apresentada no Chromagar. Uma colônia bem isolada foi replicada no meio de Infusão de Cérebro-Coração (BHI) semi-sólido e incubada a $37^{\circ} \mathrm{C}$ durante 24 horas. Após crescimento bacteriano, foi adicionado glicerol para a manutenção das amostras, sendo feito o congelamento em freezer a $-80^{\circ} \mathrm{C}$ até o final das coletas (NMC, 1999).

De acordo com o protocolo de Assis et al. (2011) e Silva et al. (2021), finalizando as coletas e o processamento para triagem das amostras, foi realizado o tratamento das amostras positivas no Chromagar para a extração das proteínas ribossomais. Após a extração, o material foi encaminhado para o Laboratório Microbiologia de Alimentos, UFLA - MG, Brasil para confirmação do microrganismo em estudo pela técnica de desreplicação (identificação de moléculas) por meio do equipamento MALDI-TOF: Espectrometria de Massas por Ionização e Dessorção a Laser Assistida por Matriz.

\subsection{Extração de proteínas para analise MALDI-TOF}

Após a triagem das colônias suspeitas de Klebsiella spp, as mesmas foram repicadas em ágar BHI e posteriormente transferidas porções bacterianas de $10 \mu \mathrm{L}$ para Eppendorf com $30 \mu \mathrm{L}$ de água deionizada, gerando uma suspensão que foi homogeneizada com pipetagens sucessivas. Em seguida a suspensão foi agitada no vórtex por 30 segundos.

Então adicionou-se $900 \mu \mathrm{L}$ de etanol puro à suspensão, que foi agitada por 30 segundos no vórtex e posteriormente colocada na centrífuga por 2 minutos a 13.000rpm. Após a centrifugação, foi removido o sobrenadante. A suspensão foi novamente centrifugada para remover toda a solução etanólica. Após esse processo, foi adicionado $50 \mu \mathrm{L}$ de ácido fórmico a $70 \%$ ao Eppendorf e homogeneizada no vórtex.

Para finalizar, foi adicionado $50 \mu \mathrm{L}$ de acetonitrila nessa suspensão e a mesma centrifugada por 2 minutos e separouse o sobrenadante (parte líquida). A massa foi descartada e as proteínas ribossomais foram encaminhadas para o Laboratório de Microbiologia de Alimentos - UFLA (Assis et al., 2011 e Silva et al., 2021).

Para a identificação definitiva e classificação dos microrganismos em questão, foi utilizado o espectrômetros do tipo MALDI-TOF (Matrix Associated Laser Desorption-Ionization). O Sistema MALDI Biotyper, usando espectrometria de massa MALDI-TOF para interpretação dos resultados, se dá por meio de indicadores de scores determinados pelo referido Sistema para identificação da microbiota em um banco de dados.

O padrão utilizado é a Escherichia coli ATCC 25922 THL, a partir da qual o equipamento busca em seu banco de dados se as características se assemelham ou não a determinando bactéria que está presente na amostra. 


\subsection{Análises estatísticas}

Foram utilizados Teste Exato de Fisher, para estudo de associação (sítios anatômicos com mão do tutor) e o Teste de Intervalo de Confiança para comparação entre grupos (sítios anatômicos animais e também mão do tutor), adotando-se p-valor $<0,05$ para significância estatística (Contador \& França, 2016).

\section{Resultados}

Dos 114 animais foram obtidas 456 amostras, destas após a triagem foram obtidas 47 amostras $(10,30 \%)$ que apresentaram características semelhantes às de Klebsiella spp de 32 animais (28,07\%). Entretanto, somente 8 amostras $(17,02 \%)$ de 7 animais $(21,87 \%)$ foram confirmadas Klebsiella pneumoniae.

Na tabela 1 é possível verificar a quantidade de animais que apresentaram a presença de Klebsiella pneumoniae sendo que na população de 114 cães a prevalência foi de $21,87 \%$ (7 animais).

Tabela 1. Relação do número de animais e a presença de Klebsiella pneumoniae confirmadas pelo MALDI-TOFF.

\begin{tabular}{ccccc}
\hline TOTAL DE & Número de & Número de amostras & Porcentagem de cães & Porcentagem de amostras \\
CÃES & cães que & confirmadas & que apresentaram & confirmadas para \\
& presença de Klebsiella & para Klebsiella & presença de Klebsiella & Klebsiella pneumoniae \\
pneumoniae & pneumoniae & \\
\hline 114 & 7 & 8 & $21,87 \%$ & $17,02 \%$ \\
\hline
\end{tabular}

Fonte: Autores.

Houve a confirmação de gênero e espécie em 9 amostras, sendo a maioria das amostras do sítio anatômico retal, contabilizando 6 amostras. Já as demais foram do prepúcio (1) e da cavidade oral (1). Quanto aos tutores, foi encontrada (1) amostra, como pode ser observado no Quadro 1.

Quadro 1. Amostras Clinicas coletadas dos sítios anatômicos (cavidade oral, retal, vaginal ou prepucial) e mão de tutores identificadas como Klebsiella pneumoniae por meio do MALDI-TOF.

\begin{tabular}{|c|c|c|c|c|c|}
\hline Amostra & $\begin{array}{c}\text { Sítio } \\
\text { Anatômico }\end{array}$ & $\begin{array}{c}\text { Primeiro } \\
\text { Organismo } \\
\text { Identificado }\end{array}$ & $\begin{array}{c}\text { Score } \\
\text { Identificador do } \\
\text { Sistema Maldi } \\
\text { Biotyper }\end{array}$ & $\begin{array}{c}\text { Segundo } \\
\text { Organismo } \\
\text { Identificado }\end{array}$ & $\begin{array}{c}\text { Score } \\
\text { Identificador do Sistema } \\
\text { Maldi Biotyper }\end{array}$ \\
\hline $\mathrm{A} 2$ & Retal & $\begin{array}{c}\text { Klebsiella } \\
\text { pneumoniae }\end{array}$ & 2.137 & $\begin{array}{c}\text { Klebsiella } \\
\text { pneumoniae }\end{array}$ & 2.023 \\
\hline A7 & Retal & $\begin{array}{c}\text { Klebsiella } \\
\text { pneumoniae }\end{array}$ & 2.057 & $\begin{array}{c}\text { Klebsiella } \\
\text { pneumoniae }\end{array}$ & 1.916 \\
\hline A9 & Retal & $\begin{array}{c}\text { Klebsiella } \\
\text { pneumoniae }\end{array}$ & 2.112 & $\begin{array}{c}\text { Klebsiella } \\
\text { pneumoniae }\end{array}$ & 2.104 \\
\hline
\end{tabular}




\begin{tabular}{|c|c|c|c|c|c|}
\hline A10 & Prepúcio & $\begin{array}{c}\text { Klebsiella } \\
\text { pneumoniae }\end{array}$ & 2.296 & $\begin{array}{c}\text { Klebsiella } \\
\text { pneumoniae }\end{array}$ & 2.193 \\
\hline B7 & Retal & $\begin{array}{c}\text { Klebsiella } \\
\text { pneumoniae }\end{array}$ & 1.845 & $\begin{array}{c}\text { Klebsiella } \\
\text { pneumoniae }\end{array}$ & 1.717 \\
\hline D3 & Oral & $\begin{array}{c}\text { Klebsiella } \\
\text { pneumoniae }\end{array}$ & 2.189 & $\begin{array}{c}\text { Klebsiella } \\
\text { pneumoniae }\end{array}$ & 2.004 \\
\hline D11 & Retal & $\begin{array}{c}\text { Klebsiella } \\
\text { pneumoniae }\end{array}$ & 2.294 & $\begin{array}{c}\text { Klebsiella } \\
\text { pneumoniae }\end{array}$ & 2.208 \\
\hline F7 & $\begin{array}{c}\text { Mão } \\
\text { Proprietário }\end{array}$ & $\begin{array}{c}\text { Klebsiella } \\
\text { pneumoniae }\end{array}$ & 2.17 & $\begin{array}{c}\text { Klebsiella } \\
\text { pneumoniae }\end{array}$ & 1.978 \\
\hline
\end{tabular}

Fonte: Autores.

Esse quadro demonstra o número de amostras, nas quais foram identificadas a presença de Klebsiella pneumoniae, o sítio anatômico em que foi encontrada e o resultado geral segundo o score identificador apresentado. O score é um identificador determinado pelo Sistema MALDI BIOTYPER para interpretação dos resultados de identificação de microrganismos em um banco de dados. Segundo os resultados de escores foi definido um ranking de primeiro e segundo lugar para o agente que teve identificação confirmada para gênero e espécie.

Não houve associação da presença de Klebsiella pneumoae nos sítios anatômicos e a mão do tutor como ficou demonstrado estatisticamente pelo Teste de Fisher (Tabela 2).

Tabela 2. Associação da presença de Klebsiella pneumoae nos sítios anatômicos.

\begin{tabular}{|c|c|c|c|c|c|}
\hline $\begin{array}{c}\text { SÍTIOS } \\
\text { ANATÔMICOS }\end{array}$ & ORAL & $\begin{array}{l}\text { VAGINAL/ } \\
\text { PREPÚCIAL }\end{array}$ & RETAL & MÃO TUTOR & CÃO GERAL \\
\hline ORAL & NS & NS & NS & NS & NS \\
\hline $\begin{array}{l}\text { VAGINAL/ } \\
\text { PREPUCIAL }\end{array}$ & NS & NS & NS & NS & NS \\
\hline RETAL & NS & NS & NS & NS & NS \\
\hline MÃO TUTOR & NS & NS & NS & NS & NS \\
\hline CÃO GERAL & NS & NS & NS & NS & NS \\
\hline
\end{tabular}

$\mathrm{NS}=$ não significativo (P-valor superior 0,05$)$.

Fonte: Autores. 
Por meio do teste de Intervalo de Confiança, fica confirmado estatisticamente uma maior presença de Klebsiella pneumoae nos animais do que nas mãos dos tutores (Tabela 3).

Tabela 3. Resultado de P-valor do Intervalo de Confiança para duas proporções os sítios anatômicos de coleta nos animais e mão do tutor.

\begin{tabular}{|c|c|c|c|c|c|}
\hline $\begin{array}{c}\text { SÍTIOS } \\
\text { ANATÔMICOS }\end{array}$ & ORAL & $\begin{array}{l}\text { VAGINAL/ } \\
\text { PREPÚCIAL }\end{array}$ & RETAL & MÃO TUTOR & CÃO GERAL \\
\hline ORAL & NS & NS & NS & NS & NS \\
\hline $\begin{array}{r}\text { VAGINAL/ } \\
\text { PREPUCIAL }\end{array}$ & NS & NS & NS & NS & NS \\
\hline RETAL & NS & NS & NS & NS & NS \\
\hline MÃO TUTOR & NS & NS & NS & NS & 0,035 \\
\hline CÃO GERAL & NS & NS & NS & NS & NS \\
\hline
\end{tabular}

NS = não significativo (P-valor superior 0,05).

Fonte: Autores.

\section{Discussão}

Dos cães que apresentaram a presença da bactéria, observou-se, na ficha de atendimento, a instalação de doenças já estabelecidas ou diagnosticadas durante o atendimento no Hospital Veterinário, como pneumonia, otite e infecção urinária doenças que possuem relação com a bactéria, o que demonstra possível relação da mesma em doenças infecciosas. Sabe-se que a Klebsiella pneumoniae é uma bactéria oportunista que se beneficia da baixa imunidade do hospedeiro para se manifestar e ocasionar doenças (Mungloo-rujubali et al., 2013).

O sistema urinário pode ser acometido por uma grande variedade de doenças (pielonefrite, urolitíase e cistite, dentre outras) que podem ocorrer em humanos (independente do sexo, idade) e animais de todas as espécies, machos ou fêmeas, jovens ou adultos (Carvalho, 2004). Apesar das bactérias Gram positivas - como Staphylococcus spp., Streptococcus spp. e Enterococcus spp. - serem causadoras de infecções no trato urinário de cães, as bactérias Gram negativas - como Escherichia coli, Proteus spp., Klebsiella spp., Pseudomonas spp. e Enterobacter spp. - são responsáveis por 75\% dos casos de ITU’s em animais de pequeno porte (Carvalho et al., 2014). Como os animais do presente estudo eram os que estavam para serem atendidos no Hospital Veterinário, por apresentares as mais diversas patologias, possivelmente poderiam ter em sua microbiota a presença de Klebsiella pneumoniae.

Outra patologia relatada na anamnese e descrita na ficha de atendimento pelo médico veterinário na triagem foi a cinomose, uma doença viral que afeta principalmente os sistemas respiratório, gastrintestinal e nervoso dos cães. Existem estudos que relatam que os animais podem apresentar infecções bacterianas concomitantemente às infecções virais, havendo relação com infecções bacterianas oportunistas (Silva et al., 2005; Almeida et al., 2009). Hirsh e Zee (2003) identificaram que 
dentre os microrganismos que são derivados do reto e do períneo, um dos mais importantes é a Klebsiella pneumoniae, sendo responsável por muitos episódios de bacteriúria em cães, tendo uma frequência de 8 a 12 \% de amostras de urina.

Souza et al. (2019) encontraram em seu estudo um total de 67 isolados de Klebsiella pneumoniae provenientes de diferentes sítios de isolamento de animais domésticos (39/67) e silvestres (28/67). Em seu estudo, assim como nos anteriores (ex. Hirsh e Zee, 2003), o maior percentual de isolamento de Klebsiella pneumoniae foi de amostras de urina, com 16\% (11/67) e também encontraram em fezes 15\% (10/67) e pulmão 13,5\% (09/67).

As taxas de portador de Klebsiella spp. diferem consideravelmente de estudo para outro e a taxa de detecção nas amostras de fezes varia de 5\% a 38\% enquanto as taxas na nasofaringe variam de $1 \%$ a $6 \%$ no homem (Zamparette, 2014). Essas taxas de portadores mudam drasticamente no ambiente hospitalar, onde as taxas de colonização aumentam em proporção direta ao tempo de permanência. A alta taxa de colonização por Klebsiella parece estar associada ao uso indiscriminado de antibióticos e não somente a fatores relacionados à prestação de cuidados no hospital. A antibioticoterapia prévia está significativamente associada ao oportunismo da Klebsiella em infectar o paciente (Zamparette, 2014).

Analisando os resultados obtidos no presente estudo, não houve correlação entre a bactéria encontrada na mão do tutor e no respectivo animal. Ewers, et al. (2014) concluíram em seu trabalho que a ocorrência frequente e a disseminação nosocomial de K. pneumoniae, produtora de CTX-M-15 resistente a múltiplos fármacos, determina os animais como uma fonte relevante de tais cepas. Se eles formam um pool uniforme com isolados humanos ou representam um grupo separado de cepas passando por uma evolução paralela, permanecem desconhecidos. Embora não haja evidência de uma transferência direta de $K$. pneumoniae multirresistente entre animais e seres humanos, novos estudos devem desvendar caminhos de transmissão relevantes dessas bactérias com risco de morte em ambas as populações.

Diante do exposto, é necessário, ao adquirir um animal doméstico, oferecer uma boa condição de vida como ambiente adequado, higiene do animal, vacinação regular contra raiva e outras doenças. Ao passear em vias públicas, o animal deve ser devidamente contido, além de o condutor responsabilizar-se pela limpeza dos dejetos de seu animal, observar alterações fisiológicas, como nas excreções: urina e fezes (Silva, 2005). Outra medida, que deve ser levada em conta, é a não utilização de antimicrobianos sem indicação médica. Somente os cuidados com o ambiente e com o bem-estar animal permitem a prevenção de fatores determinantes para o risco de incidência e prevalência de doenças.

\section{Conclusão}

Com o presente estudo foi confirmada a presença de Klebsiella pneumoniae pelo equipamento MALDI-TOF em oito cães e nas mãos de um tutor. Não houve associação da bactéria encontrada na mão do tutor com o seu animal. Fica confirmado estatisticamente uma maior presença de Klebsiella pneumoae nos animais do que nas mãos dos tutores Apesar da prevalência da bactéria ter sido baixa, não se isentam os cães de serem reservatórios para possível transmissão a humanos. E, ainda, constatou-se que mais estudos são necessários para desvendar a possibilidade de transmissão e o mecanismo para que ela ocorra. 


\section{Referências}

Almeida R.K., Vasconcelos A.C., Carneiro R.A., Paes P.R.O \& Moro L. (2009). Alterações citológicas do sangue periférico e da medula óssea de cães com cinomose. Arq. Bras. Med. Vet. Zootec., 61(6), 2-6. doi: 10.1590/S0102-09352009000600001

Aquino, S., \& Herzig, K. (2018). Klebsiella oxytoca multirresistente como agente de dermatite disseminada em cão. Acta Scientiae Veterinariae. 46(1), 324. Recuperado de https://www.bvs-vet.org.br/vetindex/periodicos/acta-scientiae-veterinariae/46-(2018)-supl/klebsiella-oxytocamultirresistent -como-agente-dedermatite-dissemina.

Assis D. M., Juliano, L \& Juliano, M.A. (2011). A espectrometria de massas aplicada na classificação e identificação de microorganismos. Revista da Universidade Vale do Rio Verde. 9(2), 344-355. doi: 10.5892/ruvrv.2011.92.344355.

Axelsson C., Rehnstam-Holm A. S. \& Nilson B. (2020) Rapid detection of antibiotic resistance in positive blood cultures by MALDI-TOF MS and an automated and optimized MBT-ASTRA protocol for Escherichia coli and Klebsiella pneumoniae, Infectious Diseases. Contribution to journal, 52(1), 45-53. doi: $10.1080 / 23744235.2019 .1682658$

Benagli C., Rossi V., Dolina M., Tonolla M \& Petrini O. (2011). Matrix-assisted laser desorption ionization-time of flight mass spectrometry for the identification of clinically relevant bacteria. Journal of Clinical Microbiology. 6 (1), 2-7. doi: 10.1111/j.1469-0691.2010.03323.x.

Brooks G. F., Carroll K. C., Butel J. S., Morse S. A. \& Mietzner T. A. (2014). Microbiologia médica de Jawetz, Melnick \& Adelberg. Porto Alegre: AMGH. 26(1), 700-872.

Carvalho V.M., Spinola T., Tavolari F., Irin K., Oliveira R. M. \& Ramos M. C. C. (2014). Infecções do trato urinário (ITU) de cães e gatos: etiologia e resistência aos antimicrobianos. Pesq. Vet. Bras. 34(1), 62-70. doi: 10.1590/S0100-736X2014000100011.

Contador J.L., Senne E. L. F. (2016). Testes não paramétricos para pequenas amostras de variáveis não categorizadas: um estudo. São Carlos: Gest. Prod. 23 (3), 588-599. doi:10.1590/0104-530x357-15.

Da Silva A. M., de Souza A. C., Assis D. M., Almeida A. C. O., Oliveira C. D. M. S., Junior L. A. A. P \& Oliveira N. D. M. S. (2021). Avaliação zootécnica de alevinos de tilápia alimentadas com kefir. Research, Society and Development, 10(2), 5-23. doi: http://dx.doi.org/10.33448/rsd-v10i2.12209.

Da Silva A.M., Melo K. M. \& de Sousa M. (2005). Sensibilização de duas comunidades vizinhas à UFRPE sobre posse responsável como medida preventiva ao abandono de animais. In: Congresso ibero americano de extensão universitária, Rio de janeiro: Anais do VIII Congresso Ibero Americano de Extensão Universitária.

Effah C.Y., Sun T., Liu S \& Wu Y. (2020). Klebsiella pneumoniae: An increasing threat to public health. Ann. Clin. Microbiol. Antimicrob. 19 (1), 2-9. doi: 10.1186/s12941-019-0343-8

Ferreira M.C., Nobre D., Oliveira de M. G. X., Oliveira de M. C. V., Cunha M. P. V., Menão M. C., Dellova D. C. A., Knöbl T. (2014). Agentes bacterianos isolados de cães e gatos com infecção urinária: perfil de sensibilidade aos antimicrobianos. Asa, São Paulo, 2(2), 29-37. http://www.revistaseletronicas.fmu.br/index.php/ASA/article/view/477/637.

Garbati M.A., Bin Abdulhak A., Baba K \& Sakkijha H. (2013). Infection due to colistin-resistant Enterobacteriacae in critically-ill patients. J Infect Dev Ctries. 7(10), 9-713. doi: 10.3855/jidc.2851.

Greene, C.E. (2006). Infectious diseases of the dog and cat. Books \& Journals. Canada: Saunders/ Elsevier, 49(9), 488. Doi: 10.1111/j.17485827.2008.00601.x.

Guardabassi L., Schwarz S \& Loyd D. H. (2004). Pet animals as reservoirs of antimicrobial-resistant bacteria. Journal of Antimicrobial Chemotherapy. 4(2), 321-332. doi: $10.1093 / \mathrm{jac} / \mathrm{dkh} 332$

Gupta A., Ampofo K., Rubenstein D \& Saiman L. (2003). Extended spectrum beta lactamase-producing Klebsiella pneumoniae infections: a review of the literature. J Perinatol, 23(6), 439-43. doi: 10.1038/sj.jp.7210973.

Hirsh, D. C \& Zee Y. C. (2003). Microbiologia veterinária. Tradução de Adriana de Souza Coutinho. São Paulo: Guanabara Koogan. 1(1), 332-446.

Hirsh D. C., Maclachlan N. J. \& Walker R. L. (2004). Veterinary Microbiology. Estados Unidos da América: Blackwell Science Inc. An International Journal. 2(1), 536-1032.

Koneman E. W \& Allen, S. (2008). Diagnostico Microbiologico/Microbiological diagnosis: Texto Y Atlas En Color/ Text and Color Atlas. Ed. Médica Panamericana. Koneman. 6(1), 1191-1691.

Lau H. Y., Huffnagle G. B \& Moore, T. A. (2008). Host and microbiota factors that control Klebsiella pneumoniae mucosal colonization in mice. Microbes and Infection. 10(12), 1283-1290. doi: 10.1016/j.micinf.2008.07.040.

Lopes H.V \& Tavares W. (2005). Diagnóstico das infecções do trato urinário. Rev. Assoc. Med. Bras. São Paulo. 51(6), 1-3. doi: 10.1590/S010442302005000600008

Marques C., Belas A., Franco A., Aboim C., Gama L.T., Pomba C. (2018). Increase in antimicrobial resistance and emergence of major international high-risk clonal lineages in dogs and cats with urinary tract infection: 16-year retrospective study. Journal Antimicrob. Chemother. 73(2), 377-384. doi:10.1093/jac/dkx401.

Miguel P. S. B., Delvaux J. C., de Oliveira M. N. V., de Camargo R., Franco M. H. R., de Araujo Sobreira H \& Jardim V. H. P. (2021). Bactérias endofíticas: Colonização, benefícios e identificação. Brazilian Journal of Development. 7(1), 8777-8791. doi:10.34117/bjdv7n1-595 
Mohammed B. J., Saleh Z. F., Esmaeel J. R., Klaif S. F., Jawad M. S., \& Fahad K. H. (2020). Identification and phylogenetic study of klebsiella pneumoniae via molecular-based techniques targeting 16s rRNA, maga, and rMPA in camels from al-diwaniyah city, iraq. Annals of Tropical Medicine and Health, 23 (5), 218-225. doi:10.36295/ASRO.2020.23526

Munoz M. A., Ahlstrom C., Rauch B. J \& Zadoks, R. N. (2006). Fecal Shedding of Klebsiella pneumoniae by Dairy Cows. Journal of Dairy Science, 89(1), 3425-3430. doi: 10.3168/jds.S0022-0302(06)72379-7.

Hogan J.S., Gonzales R.N., Harmon R.J., Nickerson S.C., Oliver S.P., Pankey J.W., Smith K.L., Hogan J., Armas-Portela R., Harmon R., Nickerson S.C, Oliver S \& Pankey J (1999). Laboratory handbook on bovine mastitis. National Mastitis Council, Madison, WI. 78(7), 485-488.

Osborne C.A \& Lees, G.E. (1995). Bacterial Infections of the Canine and Feline Urinary Tract. In: FINCO, D. R. Canine and Feline Nephrology and Urology. Williams e Wilkins, Baltimore, EUA, 1(2), 759-797.

Rios L. L., Oliveira V. T. O., Malta T. B., dos Santos G. P., \& Fortuna, J. L. (2020). Isolamento, identificação e teste de susceptibilidade aos antimicrobianos de bactérias patogênicas em vestimentas usadas por profissionais de saúde em ambiente hospitalar. Brazilian Journal of Health Review, 3(5), 12999-13027. doi:10.34119/bjhrv3n5-131

Santaniello A., Sansone M., Fioretti A., Menna L.F. (2020). Revisão Sistemática e Meta-Análise da Ocorrência do Grupo de Bactérias ESKAPE em Cães e o Risco Zoonótico Relacionado na Terapia Assistida por Animais e na Atividade Assistida por Animais no Contexto da Saúde. Jornal Internacional de Pesquisa Ambiental e Saúde Pública, 17 (9): 32-78. doi.org/10.3390/ijerph17093278.

Silva I.N.G., Guedes M.I.F., Rocha M.F.G., Medeiros C.M.O., Oliveira L.C., Moreira O.C., Teixeira, M.F.S. (2005). Perfil hematológico e avaliação eletroforética das proteínas séricas de cães com cinomose. Arquivo Brasileiro de Medicina Veterinária e Zootecnia, 57 (1), 136-139. doi:10.1590/S010209352005000100019 .

Siqueira, A. K. (2007). Fatores de virulência em linhagens de Escherichia coli isoladas de infecção do trato urinário, piometra e fezes de cães. Dissertação (mestrado) - Universidade Estadual Paulista, Faculdade de Medicina Veterinária e Zootecnia. Recuperado de http://hdl.handle.net/11449/106031.

Sousa, A. T. H. I., Makino, H., Bruno, V. C. M., Candido, S. L., Nogueira, B. S., Menezes, I. G., Nakazato, L., \& Dutra, V. (2019). Perfil de resistência antimicrobiana de Klebsiella pneumoniae isoladas de animais domésticos e silvestres. Arquivo Brasileiro de Medicina Veterinária e Zootecnia, 71(2), 584593. doi: 10.1590/1678-4162-10599

Umeh, O. (2019). Klebsiella Infections. Recuperado de http://emedicine.medscape.com/article/219907-overview.

Zetun, C. B. (2009). Análise quali-quantitativa sobre a percepção da transmissão de zoonoses em Vargem Grande, São Paulo (SP): a importância dos animais de companhia, da alimentação e do ambiente. Dissertação de Mestrado, Faculdade de Medicina Veterinária e Zootecnia, Universidade de São Paulo, São Paulo. doi:10.11606/D.10.2009.tde-01092009-140420. 